here is statistical evidence to prove that the stags with the largest antlers win the sexual battle most often; with the gaur sheer size and blackness seem to be the factors controlling dominance. The gaur is the one major herbivore that seems to be increasing in the park-because of religious prejudice against killing animals that resemble cows.

It is the study of the tiger that will interest most people. The behaviour of the tiger is clearly outlined, though the sample of animals viewed was small. The doings of one family were followed for more than a year until the cubs became independent, the male cub leaving first. Tigers are shown to be more sociable than might be expected, and their territories, marked with scent and by other means, are not inviolable; at first they are inefficient and clumsy killers, becoming more expert with practice.

Finally, the relationship between predator and prey is outlined, showing that the tiger, which is the main predator, will kill healthy animals in their prime as well as old and young. The selective nature of predation may be different in cats, which kill chiefly by stealth, from that in animals such as wolves, which kill by long pursuits, during which the health and speed of the prey is at a premium.

Dr. Schaller is almost mercilessly scientific in his approach. The text is heavily punctuated with references, which makes it difficult to read, and he is inclined to use scientific jargon. Occasional comments, which might have been stronger, stress the appalling state of wildlife conservation in India, in which parks and sanctuaries are still poached and overgrazed. It will be for the Forest Department. and those in India interested in wildlife, to see that this pioneer study is not also the last.

LESLIE BROWN

\title{
The World of the Polar Bear, by Richard Perry. Cassell, 30s.
}

In the field, under a rising spring sun, polar bears with their massive, waddling bodies and long necks, appear lemon colour against the dazzling whiteness of their home - the coastal pack ice. Moving steadily to leeward of broken lines of ice, they snuff continually, sensitive noses twitching; constantly scanning the air for scent from seal dens. Seals are their main prey, and they hunt them all round the Arctic-off the Alaskan coast, among the Canadian Arctic islands, near Greenland, Svalbard, and the islands off the north coast of Russia. For such spectacular and widely known mammals, there are surprisingly few comprehensive studies. Thus it is good to see Richard Perry's contribution appearing when it is badly needed; and besides being a handy background reference for biologists and conservationists it will have wide popular appeal.

Mr. Perry brings to bear his considerable talent as a naturalist, literature researcher and author. His goal is to collect from many sources scientific papers, volumes on polar exploration, whaling and sealing - "all that is known about polar bears in the wild state up to the autumn of 1965", and he comes close to achieving it. He covers the life of the polar bear from birth in the winter den to the final break-up of the family, with special chapters on distribution, behaviour in relation to man, and the past and future of the species. He has an easy, engaging style, and, although he evidently lacks field experience with polar bears, his deep sympathy and imagination occasionally enable him to create arctic scenes of intense reality.

Because the literature reviewed by the author is so diverse and varying in quality, and because few detailed scientific studies exist, his approach is largely anecdotal. Under the circumstances, perhaps a tighter organisation of the material under systematic headings would have been more welcome to the scientist. Nevertheless, continuity is good and he does try to present his material 
critically. A good example is his questioning of Pedersen's hypothesis of a continual circumpolar "migration" of the entire polar bear population over a period of years. There are many reasons for suspecting this idea, although polar bears do drift with the pack ice at times.

Some details mar the book, but not seriously. Photographs are tastelessly jammed together (with superimposed typewritten captions), and errors are common in the list of scientific names of Arctic animals in an appendix. But there is a useful range map, bibliography and index.

Mr. Perry concludes that polar bears have a precarious future, and that immediate, concerted action is necessary to save them. He is in an ideally neutral and well-informed position for assessing the situation, which gives the greatest force to his statement. His main concern is for the polar bear.

\section{R. HARINGTON}

\section{Mongooses, Their Natural History and Behaviour, by H. E. Hinton and A. M. S. Dunn. Oliver \& Boyd, 42s.}

Owing perhaps to the diurnal activity of many species, the mongooses are one of the better known groups of small carnivores, but as with the majority of taxonomic groups of vertebrates the relevant literature is exceedingly fragmented and scattered. Professor Hinton and Miss Dunn have therefore done a useful service in bringing together much of this information into a single volume (over 250 references are listed).

No detailed ecological study appears to have been made of any species of mongoose in its native range, and the information comes largely from casual observations on wild mongooses in Africa and Asia; from more detailed studies of introduced mongooses on the Caribbean islands and Hawaii; and (predominantly) from animals in captivity, especially the South African meerkat Suricata suricatta whose behaviour in captivity has been subjected to careful study by ethologists. In spite of the addition of chapters on mongooses in Indian folk tales, in Ancient Egypt, and as pets, the book remains a compilation of rather disjointed facts with little attempt to draw from these any overall picture of the group and little evidence of personal involvement with mongooses that might commend it for continuous reading rather than reference. A final chapter lists the 36 species of mongooses with a statement of distribution and lists of subspecies, synonyms and local names. Only for seven species is other information given under species headings, and the sixteen plates of photographs illustrate only four of the 36 species.

\section{G. B. CORBET}

Animals and Birds in Australia, by Graham Pizzey. Cassell, $£ 55$ s. This is a very pleasant introduction to the wildlife of Australia, with many fine photographs. The author deals with a hundred species, ranging from corals to possums; and here one must murmur against the title which perpetuates the idea that birds are not "animals". The arrangement in sections, under such titles as "The Great Hardwood Forests" and "Bass Strait" is rather unsatisfactory, but under each of these headings a useful sketch of the ecology and history is given. Oddly, the nearest thing to a contents list is the alphabetical list of species at the end of the book.

The book has an appeal at more levels than one. On the one hand many of the pictures-24 full-page colour plates and 250 black-and-white photographshave a charm that reaches out to the very young. On the other hand the threepage introduction includes a judicious thumbnail sketch of the past of the Australian continent as a theatre for evolution. Moreover a distribution map is provided for each species and, in an appendix, the scientific name. The text accompanying 